\title{
Effects of Social Comparison Orientation on Social Anxiety in Middle School Students and Moderating Role of Maladaptive Cognitive Emotion Regulation Strategies
}

\author{
Yujin Lee ${ }^{1}$, Ju Hee Park ${ }^{2}$ \\ M.A., Department of Child \& Family Studies, Yonsei University, Seoul, Korea ${ }^{1}$ \\ Professor, Department of Child \& Family Studies, Yonsei University, Seoul, Korea ${ }^{2}$ \\ 중학생의 사회비교 경향성이 사회불안에 미치는 영향과 부적응적인 인지적 \\ 정서조절전략의 조절효과 \\ 이유진 ${ }^{1}$, 박주희 ${ }^{2}$ \\ 연세대학교 아동가족학과 석사 ${ }^{1}$, 연세대학교 아동가족학과 교수 ${ }^{2}$
}

\begin{abstract}
Objectives: The present study aimed to examine the effects of social comparison orientation and the moderating effect of maladaptive cognitive emotion regulation strategies on social anxiety in middle school students.

Methods: The participants in this study were 442 students from four middle schools located in Seoul and Gyeonggi-do. Social anxiety, social comparison orientation, and maladaptive cognitive emotion regulation strategies were measured using Social Anxiety Scale for Adolescents (La Greca \& Lopez, 1998), Iowa-Netherlands Comparison Orientation Measure (Gibbons \& Buunk, 1999), and Cognitive Emotion Regulation Questionnaire (Garnefski, Kraaij, \& Spinhoven, 2001), respectively. The data were analyzed via descriptive statistics and hierarchical regression anaylsis.

Results: The results indicated that social comparison orientation and catastrophizing had positive influences on students' social anxiety. In addition, rumination moderated the relationship between social comparison orientation and social anxiety.

Conclusions: Social comparison orientation and catastrophizing increased social anxiety and the effect of social comparison on social anxiety differed depending on the level of rumination.
\end{abstract}

Keywords: social anxiety, social comparison orientation, maladaptive cognitive emotion regulation strategy, middle school students

\section{Introduction}

인간은 타인과 상호작용하는 사회적 상황 속에서 누구나 크고 작은 긴장감을 경험하며 살아간다. 특히 타인의 기준을 충족 시킬 수 없다고 생각하고, 자신에 대한 평가가 이루어지는 사

Corresponding Author: Ju Hee Park, Professor, Department of Child \& Family Studies, Yonsei University, 50, Yonsei-ro, Seodaemun-gu, Seoul, Korea

E-mail: juheepark@yonsei.ac.kr
회적 상황에 압도될 때 불안을 경험하게 된다. 타인의 평가가 실제로 존재하는 상황이나 혹은 존재할 것이라고 생각하는 상 상 속의 사회적 상황에서 유발되는 불안을 사회불안이라고 하 는데(Schlenker \& Leary, 1982) 이는 타인의 평가에 대한 두려 움과 사회적 상황에 대한 회피의 형태로 나타난다 $(\mathrm{La} \mathrm{Greca} \&$

(C)The Korean Association of Child Studies

This is an Open Access article distributed under the terms of the Creative Commons Attribution Non-Commercial License (http:// creativecommons.org/licenses/by-nc/4.0) which permits unrestricted noncommercial use, distribution, and reproduction in any medium, provided the original work is properly cited. 
Lopez, 1998).

이와 같은 사회불안은 그 특성상 발달적으로 자아중심적 인 사고를 통해 상상의 관중(imaginary audience)을 만들어 타 인의 주의가 자신에게 집중된다고 생각하고, 이런 상상의 청 중을 만족시키기 위해 노력하며 타인의 생각과 반응을 자신의 주관적인 생각으로 판단하는 경향이 있는 청소년들에게 더 취 약한 경향이 있다(Elkind, 1967). 더욱이 우리나라 청소년의 경 우 입시위주의 교육제도로 인해 더 많은 평가 상황에 처하며, 평가의 결과가 수치화되고 서열화 되는 환경에 노출되기 때문 에 사회불안의 위험이 더 클 수 있다. 특히 청소년기가 시작되 는 시기에 있는 중학생의 경우 타인의 평가에 대한 민감성이 급격히 증가하기 때문에 지나온 아동기에 비해 자신의 수행 능력에 대해서 의구심을 많이 가지고 수행 상황에서의 실수에 대해 더 염려하는 경향을 보인다(J.-M. Kim, 2010). 선행연구 자들(M.-K. Choi \& Min, 2015; Mesa, Nieves, \& Beidel, 2011)에 따르면, 사회불안이 높은 중학생은 또래와 긍정적이고 친밀한 관계를 맺지 못하기 때문에 또래관계에서 위축되며 고립감을 느끼고, 수행 상황에 대해 두려워하고 회피하고 싶어 하여 학 업수행 능력에 지장을 받아 학교 적응에도 어려움을 겪는 등 다양한 발달적 부적응을 초래하기 때문에 중학생의 사회불안 에 대한 이해를 증진시키고 이에 기초한 개입 방안을 고안하 는 것이 필요하다.

다수의 연구자들은 중학생의 사회불안에 영향을 미치는 것 으로 밝혀진 다양한 요인 중에서도 인지적 요인이 중요한 예 측요인으로 작용한다는 사실을 주장해왔다(Hofmann, 2007). 이는 사회불안의 경우 실제로 불안을 유발하는 요인의 존재 여부보다는 이에 대한 개인의 주관적인 인지나 해석이 사회불 안에 더 중요하게 작용하기 때문이다. 구체적으로 사회불안을 설명하는 이론적 관점을 제시한 연구자들(Clark \& Wells, 1995; Rapee \& Heimberg, 1997; Schlenker \& Leary, 1982)은 사회적 인 정과 수용의 중요성을 과도하게 생각하는 것과 같은 비합리 적 신념을 가지거나 타인에게 지각되는 자신의 모습에 지나 치게 집중하고 자신을 부정적으로 평가할 때, 혹은 모호한 사 회적 신호를 자신에 대한 위협으로 해석 하는 등 인지적 왜곡 이 나타날 때 사회불안이 유발된다고 설명하였다. 특히 몇몇 선행연구들은 다양한 인지적 요인 중에서도 사회비교 경향 성이 사회불안에 미치는 영향에 주목하였는데(Antony, Rowa,

Liss, Swallow, \& Swinson, 2005; Mitchell \& Schmidt, 2014; Seo $\& \mathrm{Kim}, 2018)$, 이는 타인과 자신을 자주 비교하는 것이 자신 과 자신이 처한 상황을 부정적으로 평가하게 만들거나, 타인 의 평가에 민감해지게 만들기 때문이다. 사회비교 경향성이란
자신의 능력과 의견을 타인과 비교하는 인지적 성향으로 정의 할 수 있는데(Gibbons \& Buunk, 1999), 사회비교 경향성이 사 회불안에 미치는 영향과 관련하여 일부 선행연구자들은 사회 비교 중에서 자신보다 높은 수준에 있는 타인과 자신을 자주 비교하는 것이 부정적인 자기 평가를 하도록 만들어 사회불안 을 야기하게 된다고 주장하였다(Antony et al., 2005; Mitchell \& Schmidt, 2014).

반면, 몇몇 연구자들은 비교의 대상과 방향에 상관없이 다 른 사람과 비교를 자주하는 것 자체가 부정적 정서 경험을 야 기한다는 상반된 의견을 제시하고 있다(White, Langer, Yariv, \& Welch, 2006). 즉, 높은 수준의 사회비교 경향성을 가진 사람은 자신을 평가할 때 내적 기준이 아닌 타인을 평가의 기준으로 삼 기 때문에 자신과 자신이 처한 상황을 객관적으로 인식하거나 평가하지 못한다. 그 결과 타인의 기준에 미치지 못했다고 판 단하고 자신과 자신의 상황을 부정적으로 평가하는 등의 인지 적 왜곡으로 인해 사회불안이 유발된다는 것이다(Seo \& Kim, 2018). 이처럼 사회비교 경향성과 사회불안의 관계에 대한 두 가지 대립된 견해가 존재하고 있으나 중학생들은 아직 자아정 체성이 확립되는 과정에 있기 때문에 자신에 대해 평가할 때 타 인과의 비교에 더 의존함으로써 타인을 기준으로 자신과 상황 을 판단할 경우 성인에 비해 더 객관적으로 해석할 수 없는 경 향이 있을 수 있다. 즉, 상향비교에만 국한되지 않고 어떤 방향 으로든지 타인과 자신을 자주 비교하는 경향으로 인해 사회적 상황에 대한 염려가 증가하고 자신의 실수에 대해 지나치게 부 정적으로 생각하기 때문에 사회불안을 경험할 가능성이 커질 수 있다(Ha, 2006). 따라서 중학생들의 경우 비교의 방향에 관 계없이 사회비교 경향성이 사회불안을 유발하는 요인으로 작 용할 수 있으므로 이러한 가능성을 검증해 보는 것이 필요하다.

그러나 사회비교 경향성이 사회불안에 미치는 영향은 자신 과 자신의 상황에 대해 얼마나 더 왜곡하여 인지하는지에 따 라 다를 수 있다. 스트레스 상황에서 야기된 정서를 인지적으 로 다루는 개인의 대처능력인 인지적인 정서조절전략 중에 사 건에 대해 부정적인 측면을 강조하고 확대함으로써 부정적 인 정서를 야기하는 전략을 부적응적인 인지적 정서조절전략 (Garnefski, Kraaij, \& Spinhoven, 2001)이라고 하는데, 이는 사회 비교 경향성이 사회불안에 미치는 영향을 악화시키거나 완충 할 수 있다. 사회비교 경향성이 높은 사람은 상황을 객관적으 로 인지하는 것이 어려워 사회불안을 경험할 수 있는데, 부적 응적인 인지적 정서조절전략을 사용하는 경우 부정적인 사고 와 정서가 유발되어 사회불안이 더 심화될 수 있다. 이를 뒷받 침하는 근거로써 사회불안을 설명하는 Hofmann (2007)의 인 
지적 요인의 통합적 모델에 따르면, 위협적으로 인식되는 사회 적 상황에서 자신이 정서적 반응을 통제할 수 없다고 생각하 고, 타인이 이를 알아챌 것이라고 믿을 때, 사회적 상황을 더 두 려워하게 되고 피하게 된다고 한다. 즉, 사회적 상황을 객관적 으로 인식하지 못하기 때문에 낮은 평가를 받거나 거부를 당 하는 등 실제보다 더 부정적인 결과가 초래될 것이라고 왜곡된 인지를 하는 사람이 야기되는 부정적인 정서를 조절하지 못하 면 통제감을 잃고 그 상황에 압도되기 때문에 더 높은 수준의 사회불안을 경험할 수 있다는 것이다(Hofmann, 2005). 이와 같 이 사회비교 경향성이 사회불안에 미치는 영향이 부정적인 인 지적 정서조절전략에 따라 다를 수 있다는 가능성이 시사됨에 도 불구하고 이를 실제로 검증한 연구는 아직 없으나, 부적응 적인 인지적 정서조절전략이 사회비교 경향성과 사회불안의 관계에서 조절효과가 있음을 밝힐 수 있다면 사회비교 경향성 이 높은 경우라고 하더라도 사회불안을 감소시키기 위한 대안 적 방법을 고안하는 데 기여할 수 있을 것이다.

한편, 부적응적인 인지적 정서조절전략은 사회비교 경향 성이 사회불안에 미치는 영향을 조절하기도 하지만 사회불안 에 직접적인 영향을 미칠 수도 있다(Aldao, Jazaieri, Goldin, \& Gross, 2014; D. Lee \& Park, 2017). 인지적 정서조절전략 중에 서도 사회불안을 유발하는 요인으로써 적응적인 인지적 정서 조절전략보다 부적응적인 인지적 정서조절전략이 중요한 이 유는 사회불안이 자신과 자신이 처한 상황에 대해 부정적으로 평가하는 사고와 같은 인지적 왜곡과 현실적으로 성취하기 어 려운 비합리적 신념을 가지는 것으로 인해 유발되기 때문이 다(Clark \& Wells, 1995; Rapee \& Heimberg, 1997; Schlenker \& Leary, 1982). 즉, 발생한 상황에 대해 긍정적으로 해석하지 않 는 것보다 부정적으로 해석하는 것을 통해 더 잘 설명될 수 있 기 때문이라고 할 수 있다(Aldao et al., 2014).

선행연구자들은 각각의 부적응적인 인지적 정서조절전략이 사회불안의 예측 요인으로 작용할 수 있는 이유를 다음과 같 이 설명하였다. 우선 자기비난은 타인에게 지각되는 자신의 무 능력하고 매력적이지 않은 모습을 강조함으로써 부정적인 사 건에 대해 스스로를 비난하는 것으로 타인의 부정적인 평가를 예상하기 때문에 사회불안이 유발될 수 있고, 타인비난의 경우 는 인간관계에서 분노와 같은 부정적인 감정을 야기하여 사회 적 상황을 회피하게 만들 수 있다(Gilbert \& Miles, 2000; D. Lee $\&$ Park, 2017). 다음으로 반추 전략을 사용하게 되면 사건과 관 련된 자신의 부정적인 측면을 지속적으로 되짚어 생각하기 때 문에 사회불안이 유발될 가능성이 높아질 수 있으며(Mellings \& Alden, 2000; You, Kim, \& Kang, 2018), 부정적 사건에 대해
서 최악의 상황이라고 생각하는 파국화 전략을 많이 사용할 경 우 사회적 상황에 대해 최악의 상황을 상상함으로써 그와 같은 상황을 회피하고 싶어 하기 때문에 사회불안이 야기될 수 있다 (Stopa \& Clark, 2000). 비록 자기비난, 타인비난, 반추 그리고 파 국화가 모두 사회불안에 정적인 영향을 미칠 것으로 가정되나, 그 영향력을 비교해봄으로써 사회불안 감소를 위한 보다 구체 적인 개입 방안을 마련하는 데 도움을 줄 수 있을 것이다.

이상의 필요성에 근거하여 본 연구에서는 사회비교 경향 성과 부적응적인 인지적 정서조절전략의 하위요인인 자기비 난, 타인비난, 반추 그리고 파국화 전략이 중학생의 사회불안 에 미치는 영향을 알아보고, 사회비교 경향성이 중학생의 사 회불안에 미치는 영향을 부적응적인 인지적 정서조절전략이 조절하는지 검증하고자 한다. 이 때 청소년의 성에 따라 사회 불안의 수준이 다르다는 선행연구 결과(Inderbitzen-Nolan \& Walters, 2000; Yang, Yang, \& Oh, 2008)에 따라 성을 통제변인 으로 분석에 포함시키고자 한다. 본 연구의 결과는 중학생의 사회불안에 대한 이해를 증진시키고, 초기 청소년 시기의 사 회불안에 대한 구체적인 중재 방안을 계획하는 데 활용될 것 으로 기대된다. 본 연구에서 선정한 연구문제는 다음과 같다.

\section{연구문제 1}

사회비교 경향성과 부적응적인 인지적 정서조절전략은 중학 생의 사회불안에 어떠한 영향을 미치는가?

\section{연구문제 2}

부적응적인 인지적 정서조절전략은 사회비교 경향성이 중학 생의 사회불안에 미치는 영향을 조절하는가?

\section{Methods}

\section{연구대상}

본 연구의 대상은 서울시 광진구, 노원구, 중구와 안양시에 위 치한 4개 중학교에 재학 중인 1-3학년 학생 442명이었으며, 연 구 대상의 선정은 편의표집 방식으로 이루어졌다. 연구 대상 은 남학생이 247명(55.9\%)로 여학생들보다 다소 많았고, 학년 의 경우 1 학년(43.0\%), 2 학년(29.0\%), 3학년(27.1\%) 순으로, 1 학년이 2 학년과 3 학년보다 더 많은 비율을 차지하였다. 주관 적 경제적 수준의 경우는 중(48.2\%) 혹은 중상(34.2\%)의 응답 이 가장 많았다. 


\section{연구도구}

\section{사회불안}

중학생의 사회불안을 측정하기 위해 La Greca와 Lopez (1998) 가 개발하고, Yang 등(2008)이 번안하여 타당화한 '한국판 청 소년 사회불안 척도(Korean version of Social Anxiety Scale for Adolescents [K-SAS-A] '를 사용하였다. 타인의 부정적 평가에 대한 두려움, 새로운 상황에 대한 회피와 불안, 그리고 일반적 상황에 대한 회피와 불안을 측정하는 총 18 개의 문항으로 구 성되어 있다. 각 문항은 전혀 그렇지 않다(1점)에서부터 항상 그렇다(5점)까지 5점 척도로 평정하도록 되어있다. 문항의 예 로는 "다른 사람들이 나를 싫어할까봐 겁난다.", “잘 모르는 사람과 있으면 수줍음을 탄다.”, “다른 사람이 싫다고 할까봐 무엇인가를 같이 하자고 말하기가 겁난다.” 등이 있다. 가능한 총점의 범위는 18 점에서 90 점이며, 점수가 높을수록 타인의 평가를 두려워하고 사회적 상황을 회피하고 싶어하는 등 사회 불안의 수준이 높다는 것을 의미한다. 본 연구에서 산출된 해 당 척도의 내적합치도 계수 Cronbach's $\alpha$ 는 .94이었다.

\section{사회비교 경향성}

중학생의 사회비교 경향성은 Gibbons와 Buunk (1999)가 개발 한 Iowa-Netherlands Comparison Orientation Measure (INCOM) 을 Y.-H. Choi (2003)가 번안하고 Baek (2018)이 수정.보완한 도 구를 사용하여 측정하였다. 척도는 총 11 개 문항으로 구성되어 있으며, 측정 문항의 내용은 자신의 성취 혹은 능력 수준을 타 인의 수준과 비교하는 것이나 동일한 상황에 대한 자신의 의견 과 타인의 의견을 비교하는 것을 포함하고 있다. 문항의 예로 는 "나는 내가 인생에서 성취한 것과 다른 사람들이 성취한 것 을 비교한다.”와 “나는 나와 비슷한 문제를 겪는 사람들이 어 떤 생각을 가지고 있는지 의견을 알고자 한다.” 등이 있다. 본 척도는 5점 척도로 전혀 그렇지 않다(1점)에서 항상 그렇다(5 점)로 평정하도록 되어 있다. 전체 문항 중 5 번과 11 번의 두 개 문항은 역채점을 하도록 되어 있다. 가능한 총점의 범위는 11 점 55점까지로 점수가 높을수록 성취, 능력 수준과 의견 등에 서 타인과 자신을 자주 비교한다는 것을 의미한다. 본 연구에 서 산출된 내적합치도 계수 Cronbach's $\alpha$ 는 .80이었다.

\section{부적응적인 인지적 정서조절전략}

중학생의 부적응적인 인지적 정서조절전략을 측정하기 위해
사용한 도구는 S.-H. Kim (2004)이 번안하고 수정한 Garnefski 등(2001)의 인지적 정서조절전략 척도(Cognitive Emotion Regulation Questionnaire [CERQ])였다. 원척도는 적응적인 인 지적 정서조절전략에 관련된 20개 문항과 부적응적인 인지적 정서조절전략에 관련된 16 개의 문항을 포함한 총 36 개 문항으 로 구성되어 있다. 본 연구에서는 이 중 부적응적인 인지적 정 서조절전략의 하위요인들을 측정하는 16 개 문항을 사용하였 다. 부적응적인 인지적 정서조절전략은 자기비난, 타인비난, 반추, 그리고 파국화를 포함하며 각 하위요인 별로 4 개의 문항 씩 구성되어 있다. 각각의 예로는 "기본적으로 그 일의 원인이 분명히 나한테 있다고 생각한다.", “나는 그 일이 다른 사람 잘 못이라고 생각한다." "그 상황에서 일어났던 나의 감정을 되짚 어 생각한다.", "그 상황이 얼마나 끔찍했는지 계속해서 생각한 다.” 등이 있다. 각 문항은 전혀 그렇지 않다(1점)에서 항상 그 렇다(5점)까지 5점 척도로 평정하게 되어 있으며, 각 하위요인 의 점수 범위는 4 점에서 20 점까지로, 점수가 높을수록 해당 인 지적 정서조절전략을 더 많이 사용하는 것을 의미한다. 본 연 구에서 산출된 내적합치도 계수 Cronbach's $\alpha$ 는 자기비난의 경 우 .77, 타인비난은 .82, 반추는 .72, 그리고 파국화는 .78이었다.

\section{연구절차}

본 연구의 자료 수집은 2018년 9월 서울시와 경기도에서 편의 표집한 총 네 개 중학교에서 이루어졌다. 연구자가 중학교 교 사들을 섭외하여 연구에 대해 소개하고, 질문지의 목적, 예상 되는 소요시간과 응답 시 유의사항에 대해 설명하는 절차를 거쳤다. 교사들이 연구에 대해 간단히 소개한 후 응답한 내용 은 연구를 위해서만 사용될 것이라고 알린 후 참여에 동의한 중학생을 대상으로 질문지를 배부하고 중학생들이 자기보고 식으로 직접 응답한 질문지를 회수하는 방식으로 조사를 진행 하였다. 총 490 부의 질문지가 배부하였으며, 그 중 476부를 회 수하여 회수율은 약 $97 \%$ 였다. 회수된 질문지 가운데 한 개 이 상의 척도에서 전체 문항에 응답하지 않은 자료와, 두 개 이상 의 척도에서 동일한 번호에 일괄적으로 응답한 자료 등을 불 성실한 답변이라고 판단하여 이에 해당하는 34 부를 제외한 후에 총 442 부의 자료를 최종 분석에 사용하였다.

\section{자료분석}

본 연구에서 수집한 자료는 SPSS 24.0 (IBM Co., Armonk, NY) 을 사용하여 다음과 같이 분석하였다. 첫째, 중학생의 사회불 
안과 사회비교 경향성, 부적응적인 인지적 정서조절전략(자 기비난, 타인비난, 반추, 파국화)의 일반적 경향을 알아보기 위해 각 측정 변인 별로 평균과 표준편차를 산출하였다. 둘째, 중학생의 사회비교 경향성과 부적응적인 인지적 정서조절전 략(자기비난, 타인비난, 반추, 파국화)이 사회불안에 미치는 영향을 알아보기 위해 측정 변인들 간의 Pearson 적률상관계 수를 산출하였고, 이후 통제변인으로서 대상의 성을 투입한 위계적 중다회귀분석을 실시하였다. 셋째, 중학생의 사회비 교 경향성이 사회불안에 미치는 영향을 부적응적인 인지적 정 서조절전략(자기비난, 타인비난, 반추, 파국화)이 조절하는지 알아보기 위하여 Baron과 Kenny (1986)가 제시한 절차에 따라 위계적 중다회귀분석의 3 단계에서 사회비교 경향성과 자기 비난, 사회비교 경향성과 타인비난, 사회비교 경향성과 반추, 그리고 사회비교 경향성과 파국화의 상호작용항을 추가로 투 입하였다. 해당 단계에서 발생할 수 있는 다중공선성의 문제 를 줄이기 위하여 독립변인과 조절변인을 평균중심화(meancentering)하였으며, 잔차항들의 상관관계를 확인하기 위해 Durbin-Watson 값을 산출하였다. 사회비교 경향성이 사회불 안에 미치는 영향에 대한 부적응적인 인지적 정서조절전략의 조절효과를 구체적으로 알아보기 위해 Aiken과 West (1991) 가 제안한 단순기울기검증(simple slope analysis)과 Paternoster, Brame, Mazerolle과 Piquero (1998)가 제시한 $Z$-검정을 추가로 실시하였다.

\section{Results}

\section{측정 변인들의 일반적 경향}

본 연구에서 측정한 중학생의 사회불안, 사회비교 경향성, 부 적응적인 인지적 정서조절전략(자기비난, 타인비난, 반추, 파
국화)의 가능한 점수 범위, 평균 및 표준편차, 문항평균 점수는 Table 1에 제시된 바와 같다.

먼저 중학생의 사회불안 총점의 평균은 44.19 으로써 총점 평균을 5점 척도의 문항 평균 점수로 환산하였을 때 2.46점이 었으며, 이는 2점의 거의 그렇지 않다와 3점의 보통이다의 중 간값보다 높은 수준이다. 이것은 본 연구에 참여한 중학생들 의 사회불안이 중간보다 다소 낮은 편임을 의미한다. 다음으 로 사회비교 경향성 총점의 평균은 33.10점으로, 5점 척도의 문항 평균 환산 점수는 3.00점이었다. 이 수치는 보통이다(3 점)의 점수로서 본 연구에 참여한 중학생들의 타인과 자신을 비교하는 성향은 비교를 하지 않는 것과 많이 하는 것의 중간 정도임을 보여주었다. 마지막으로 부적응적인 정서조절전략 (자기비난, 타인비난, 반추, 파국화)의 총점 평균을 하위요인 별로 살펴보면 자기비난 3.24점, 타인비난 2.46점, 반추 3.17점 그리고 파국화 2.64점이었다. 이를 4점 척도 문항 평균 점수로 환산할 경우, 자기비난은 3.24점으로 3점의 보통이다와 4점의 자주 그렇다의 중간값과 비교했을 때 조금 더 높은 점수에 해 당하였다. 타인비난은 2.46점으로 2점의 거의 그렇지 않다와 3 점의 보통이다의 중간값보다 다소 낮은 수준이었다. 반추는 3.17점으로 중간점수보다 더 높은 수준이었고, 파국화는 2.64 점으로 중간값보다 다소 낮은 것으로 측정되었다. 요약하면 본 연구에 참여한 중학생들이 타인비난 전략과 파국화 전략을 사용하는 수준은 중간보다 낮은 편이고, 자기비난 전략과 반 추 전략을 사용하는 수준은 중간보다 다소 높은 편이다.

\section{중학생의 사회비교 경향성과 부적응적인 인지 적 정서조절전략이 사회불안에 미치는 영향}

연구문제 1 과 관련하여 중학생의 사회비교 경향성과 부적응 적인 인지적 정서조절전략이 사회불안에 미치는 영향을 검증 하기 위한 기초분석으로 각 연구 변인들 간의 상관관계를 알

Table 1

Means and Standard Deviations of the Variables

\begin{tabular}{lccc}
\hline \multicolumn{1}{c}{ Variables } & Score range & $M(S D)$ & Mean of item score \\
\hline Social anxiety & $18-90$ & $44.19(13.91)$ & 2.46 \\
Social comparison orientation & $11-55$ & $33.10(6.60)$ & 3.00 \\
Self-blame & $4-20$ & $12.97(3.20)$ & 3.24 \\
Blaming others & $4-20$ & $9.85(3.31)$ & 2.46 \\
Rumination & $4-20$ & $12.69(3.16)$ & 3.17 \\
Catastrophizing & $4-20$ & $10.57(3.52)$ & 2.64 \\
\hline
\end{tabular}

Note. $N=442$. 
아보고자 Pearson의 적률상관계수를 산출하였다. 분석 결과는 다음 Table 2 와 같다.

다음으로 중학생의 사회비교 경향성과 부적응적인 인지 적 정서조절전략(자기비난, 타인비난, 반추, 파국화)이 사회불 안에 미치는 영향을 알아보기 위하여 위계적 중다회귀분석을 실시하였다. 투입된 독립변인의 공차한계는 . $57 \sim 1.00, \mathrm{VIF}$ 는 $1.00 \sim 1.68$ 로 나타나 다중공선성의 문제가 심각하지 않음을 보여주었다. 또한 잔차항들의 상관관계를 알아보고자 산출한 Durbin-Watson 값은 1.90 으로 잔차들 간에 상관관계가 없어 회귀모형이 적합한 것을 확인하였다. 분석결과는 Table 3 에 제
시된 바와 같다. 통계분석 결과, 전체 회귀모형은 유의한 것으 로 나타났다 $(F=26.60, p<.001) .1$ 단계에 투입된 통제변인인 성 $(\beta=.11, p<.001)$ 은 사회불안을 유의하게 예측하는 것으로 나타났으며, 사회불안 변량의 $4 \%$ 를 설명하였다 $(F=16.23, p<$ .001). 2단계에 투입된 변인들 중에는 사회비교 경향성 $(\beta=.31$, $p<.001)$ 과 부적응적인 인지적 정서조절전략 중에 파국화 $(\beta=$ $.34, p<.001)$ 가 사회불안에 유의한 정적 영향을 미치는 것으 로 나타났다. 구체적으로 사회비교 경향성이 높을수록, 그리 고 파국화 전략을 많이 사용할수록 사회불안을 경험할 가능성 이 더 높았다. 2 단계에 투입된 독립변인들은 사회불안 변량 중

Table 2

Correlation Coefficients Among the Variables

\begin{tabular}{|c|c|c|c|c|c|c|c|}
\hline Variables & 1 & 2 & 3 & $4-1$ & $4-2$ & $4-3$ & $4-4$ \\
\hline 1. Gender & - & & & & & & \\
\hline 2. Social anxiety & $.19^{* * *}$ & - & & & & & \\
\hline 3. Social comparison orientation & $.26^{* * *}$ & $.42^{* * *}$ & - & & & & \\
\hline 4-1. Self-blame & .07 & $.22^{* * *}$ & $.27^{* * *}$ & 一 & & & \\
\hline 4-2. Blaming others & -.05 & $.12^{*}$ & $.15^{* *}$ & $-.16^{* *}$ & 一 & & \\
\hline 4-3. Rumination & .08 & $.24^{* * *}$ & $.36^{* * *}$ & $.47^{* * *}$ & $.22^{* * *}$ & - & \\
\hline 4-4. Catastrophizing & .01 & $.40^{* * *}$ & $.32^{* * *}$ & $.36^{* * *}$ & $.41^{* * *}$ & $.53^{* * *}$ & - \\
\hline
\end{tabular}

Note. $N=442$.

${ }^{*} p<.05 .{ }^{* *} p<.01 .{ }^{* * *} p<.001$.

Table 3

Hierarchical Regression Analysis: Effects of Social Comparison Orientation and Maladaptive Cognitive Emotion Regulation Strategies on Social Anxiety and the Moderating Role of Maladaptive Cognitive Emotion Regulation Strategies

\begin{tabular}{|c|c|c|c|c|c|c|}
\hline \multirow[b]{2}{*}{ Variables } & \multicolumn{2}{|c|}{ Step 1} & \multicolumn{2}{|c|}{ Step 2} & \multicolumn{2}{|c|}{ Step 3} \\
\hline & $B$ & $\beta$ & $B$ & $\beta$ & $B$ & $\beta$ \\
\hline Gender & 5.29 & $.19^{* * *}$ & 3.00 & $.11^{*}$ & 3.15 & $.11^{* *}$ \\
\hline Social comparison orientation & & & .64 & $.31^{* * *}$ & .66 & $.31^{* * *}$ \\
\hline \multicolumn{7}{|l|}{ Maladaptive cognitive emotion regulation strategies } \\
\hline Self-blame & & & .13 & .03 & .08 & .02 \\
\hline Blaming others & & & -.18 & -.04 & -.16 & -.04 \\
\hline Rumination & & & -.26 & -.06 & -.20 & -.04 \\
\hline Catastrophizing & & & 1.33 & $.34^{* * *}$ & 1.33 & $.34^{* * *}$ \\
\hline Social comparison orientation $\times$ Self-blame & & & & & -.02 & -.04 \\
\hline Social comparison orientation $\times$ Blaming others & & & & & -.04 & -.06 \\
\hline Social comparison orientation $\times$ Rumination & & & & & .08 & $.14^{*}$ \\
\hline Social comparison orientation $\times$ Catastrophizing & & & & & .03 & .05 \\
\hline$R^{2}$ & \multicolumn{2}{|c|}{.04} & \multicolumn{2}{|c|}{.27} & \multicolumn{2}{|c|}{.29} \\
\hline$\triangle R^{2}$ & & & \multicolumn{2}{|c|}{$.23^{* * *}$} & \multicolumn{2}{|c|}{$.02 *$} \\
\hline$F$ & \multicolumn{2}{|c|}{$16.23^{* * *}$} & \multicolumn{2}{|c|}{$26.60^{* * *}$} & \multicolumn{2}{|c|}{$17.25^{* * *}$} \\
\hline
\end{tabular}

Note. $N=442$.

${ }^{*} p<.05 .{ }^{* *} p<.01 .{ }^{* * *} p<.001$. 
추가로 $23 \%$ 를 설명하여 전체 회귀방정식에 포함된 변인들은 중학생의 사회불안 변량의 총 $27 \%$ 를 설명하였다.

\section{중학생의 사회비교 경향성이 사회불안에 미치는 영향에 대한 부적응적인 인지적 정서조절전략의 조절효과}

연구문제 2 와 관련하여 중학생의 사회비교 경향성이 사회불 안에 미치는 영향에 대한 부적응적인 인지적 정서조절전략의 조절효과를 검증하기 위하여 Baron과 Kenny (1986)가 제시한 절차에 따라 위계적 중다회귀분석을 실시하였다. 1 단계에는 성을 통제변인으로 투입하였고, 2단계에서는 사회비교 경향 성과 부적응적인 인지적 정서조절전략(자기비난, 타인비난, 반추, 파국화)을 투입하였으며, 3 단계에는 사회비교 경향성과 부적응적인 인지적 정서조절전략 하위요인들의 상호작용항 을 만들어서 투입하였다. 투입된 독립변인과 상호작용항의 공 차한계는 .50 .92, VIF는 $1.10 \sim 2.00$ 으로 나타나 다중공선성 의 문제가 심각하지 않음을 보여주었다. 또한 잔차항들의 상 관관계를 알아보고자 산출한 Durbin-Watson 값은 1.90 으로 잔 차들 간에 상관관계가 없어 회귀모형이 적합한 것을 확인하였 다. 분석 결과는 Table 3 에 제시되어 있는 바와 같다. 통계분석 결과, 전체 회귀모형은 유의한 것으로 나타났다 $(F=17.25, p<$ .001). 3 단계에 투입한 네 개 상호작용항 중에서 사회비교 경 향성와 반추의 상호작용항만 통계적으로 유의한 것으로 나타 났다 $(\beta=.14, p<.05)$. 이는 사회비교 경향성이 사회불안에 미 치는 영향은 반추 전략의 사용 수준에 따라 다름을 의미한다. 반면 사회비교 경향성과 자기비난 상호작용항, 사회비교 경향 성과 타인비난 상호작용항, 사회비교 경향성과 파국화 상호작 용항은 유의하지 않았다. 3 단계에 투입된 상호작용항은 추가 적으로 $2 \%$ 를 설명하여 전체 회귀방정식에 포함된 변인들은 중학생의 사회불안 변량의 총 $29 \%$ 를 설명하였다.

한편, 반추 전략의 사용 수준에 따라 사회비교 경향성과 사 회불안의 관계가 어떻게 달라지는지 구체적으로 알아보기 위 하여 독립변인과 조절변인의 평균값을 기준으로 상중하 세 집단으로 구분한 뒤, 각 집단의 종속변인의 평균값을 산출하 였다. 또한 Aiken과 West (1991)가 제안한 바에 기반하여 반추 전략 평균에서 1 표준편차를 더한 값, 평균에서 1 표준편차를 뺀 값을 반추 전략 사용 수준 상 집단, 중 집단 그리고 하 집단 을 구분하는 기준으로 삼고, 각각의 집단에서 독립변인과 종 속변인의 회귀계수를 산출하여 단순기울기검증(simple slope analysis)을 하였다. 이를 비교한 결과는 각각 Figure 1과 Table 4
에 제시된 바와 같다.

분석결과를 살펴보면, 반추 전략 상 집단 $(n=78)$ 의 회귀계 수는 $.53(p<.001)$, 반추 전략 중 집단 $(n=273)$ 의 회귀계수는 .33 ( $p$ <.001), 반추 전략 하 집단 $(n=91)$ 의 회귀계수는 .23 ( $p$ $<.05)$ 로 나타났다. 이는 사회비교 경향성이 높은 중학생들이 사회불안을 경험할 가능성이 더 높은데, 사회비교 경향성이 사회불안에 주는 영향이 반추 전략 사용 수준 중 집단과 하 집 단보다 상 집단에서 더 크다는 것을 보여준다.

다음으로 반추 전략의 수준에 따라 사회비교 경향성과 사 회불안의 회귀계수에 통계적으로 유의미한 차이가 있는지 알 아보기 위해 Paternoster, Brame, Mazerolle과 Piquero (1998)가 제시한 $Z$-검정을 실시하였다. 각 모형의 비표준화 회귀계수와 표준오차를 이용하여 $Z$ 값을 구하였고, 산출된 값은 Table 5에 제시하였다. $Z$ 값이 1.96 이상이면 .05수준에서, 2.58 이상이라

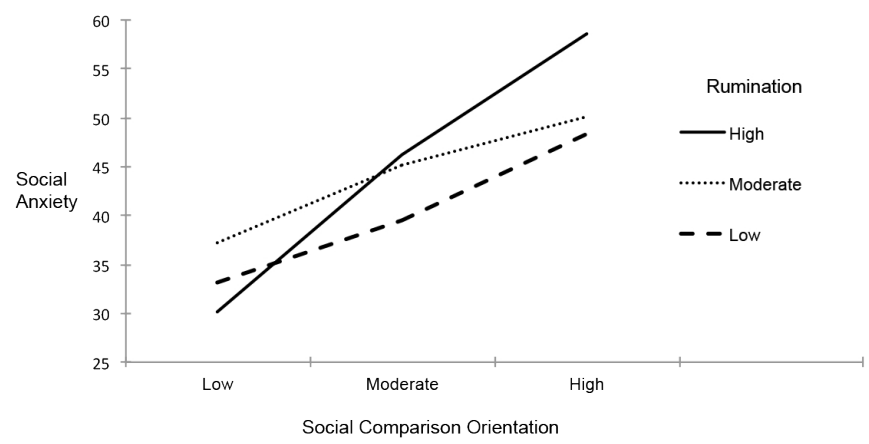

Figure 1. Moderating effects of rumination on the relationship between social comparison orientation and social anxiety.

Table 4

Simple Slope Analysis of Low, Moderate, and High Rumination Groups

\begin{tabular}{lrrrc}
\hline & \multicolumn{4}{c}{ Simple slope analysis } \\
\cline { 2 - 5 } \multicolumn{1}{c}{ Rumination } & $B$ & $S E$ & $\beta$ & $p$ \\
\hline High group $(n=78)$ & 1.226 & .23 & $.53^{* * *}$ & .000 \\
Moderate group $(n=273)$ & .706 & .12 & $.33^{* * *}$ & .000 \\
Low group $(n=91)$ & .466 & .22 & $.23^{*}$ & .034 \\
\hline
\end{tabular}

Note. $N=442$.

${ }^{*} p<.05 .{ }^{* * *} p<.001$.

Table 5

Z-test for the Equality of Regression Coefficients

Comparison of low, moderate, and high rumination groups

High group and moderate group

2.01

High group and low group

Moderate group and low group 
면 .01수준에서 유의하다.

본 연구에서 반추 전략 사용 수준에 따른 사회비교 경향성 과 사회불안의 회귀계수 간에 차이가 있는지 알아보기 위해 산출한 $Z$ 값은 상 집단과 중 집단 간에는 2.01 , 상 집단과 하 집 단 간에는 2.39 으로 .05 수준에서 각각의 회귀계수가 통계적 으로 유의미한 차이가 있었다. 즉, 반추 전략 사용 수준 상 집 단에서는 반추 전략 사용 수준 중 집단과 하 집단에 비해 사회 비교 경향성이 사회불안에 미치는 영향이 더 크다는 것을 알 수 있다. 반면, 반추 전략 사용 수준 중 집단과 하 집단의 회귀 계수 간에는 통계적으로 유의미한 차이가 없었다. 즉, 반추 전 략 사용 수준 중 집단과 하 집단의 경우 사회비교 경향성이 사 회불안에 미치는 영향이 다르지 않다는 것을 의미한다.

\section{Discussion}

본 연구는 사회비교 경향성과 부적응적인 인지적 정서조절전 략(자기비난, 타인비난, 반추, 파국화)이 중학생의 사회불안에 영향을 미치는지 알아보고, 사회비교 경향성과 사회불안의 관 계에서 부적응적인 인지적 정서조절전략의 조절효과를 검증 하였다. 본 연구를 통해 얻은 주요 연구결과들을 논의하면 다 음과 같다.

연구문제 1 과 관련하여 첫째, 중학생의 사회비교 경향성은 사회불안에 정적인 영향을 미치는 것으로 나타났다. 이는 타 인과 자신을 자주 비교하는 중학생의 경우 타인의 부정적인 평가를 두려워하고 사회적인 상황을 회피하는 경향이 있음을 의미하며 선행연구의 결과를 지지한다(Seo \& Kim, 2018). 이 와 같은 결과는 다음과 같이 해석해 볼 수 있다. 사회비교 경향 성이 높은 사람들은 타인을 자기 평가의 기준으로 두는데 이 경우 자신과 자신의 상황에 대해 객관적으로 인식하거나 평가 하지 못하게 된다. 사회비교를 자주 하는 사람들은 지속적으 로 타인의 존재를 인식하게 되고, 타인이 나를 어떻게 생각할 지에 대해 필요 이상의 관심을 기울일 수 있다. 이는 자신과 상 황에 대해 인지적으로 왜곡하는 것과 타인의 시선과 평가에 민감한 것에 의해 사회불안이 유발되고 유지된다는 Clark과 Wells (1995)의 연구와 자신의 수행을 예상되는 타인의 기준 과 비교하는 것이 사회불안을 초래한다는 Rapee와 Heimberg (1997)의 주장과 일맥상통하는 것이다. 이상의 결과에 기초하 여 사회비교 경향성이 중학생의 사회불안에 미치는 영향을 감 소시키기 위한 개인, 학교, 그리고 사회적 차원의 실천적 방안 을 제시하면 다음과 같다.
우선 개인적 차원에서는 사회비교 경향성이 사회불안에 미 치는 영향을 줄이기 위해 중학생들이 자신을 평가하는 데 있 어서 타인을 기준으로 삼지 않고 자신의 내적인 생각과 감정 에 더 집중하도록 도울 필요가 있다. 자신의 생각과 감정에 주 의를 기울이는 사람들은 외부의 기준에 의존하지 않고 자신 에 대해 보다 정확한 인식을 한다고 보고되기 때문에(Franzoi, 1983 ) 자신 혹은 자신의 상황을 보다 객관적으로 인지함으로 써 사회불안을 줄일 수 있을 것으로 사료된다. 뿐만 아니라 이 와 같은 개인적 차원에서의 개입과 함께 학교 차원의 개입으 로써 경쟁학습이 아니라 협동학습이 이루어지는 교육환경으 로 변화하는 것도 필요하다. 우리나라 중학교는 또래와의 경 쟁이 강조되는 상대적 평가와 입시 위주의 교육환경을 가지 기 때문에 중학생들은 또래와 자신을 비교해야 하는 상황에 많이 노출되는데 $(\mathrm{Ha}, 2006)$, 이를 공동의 학습목표를 성취하 기 위해 모둠 형태로 공부하는 협동학습 방법으로 전환할 필 요가 있다(S.-S. Lee \& Jang, 2007). 이러한 협동학습이 이루어 지는 교육환경에 있는 학생들은 자신의 성취를 또래와 비교를 할 필요가 없고 공동의 목표를 가지는 환경에서 사회비교 경 향성이 감소될 수 있을 것이다. 이와 연속선상에서 사회적 차 원에서의 개입도 고려할 필요가 있는데, 이는 우리나라가 관 계 중심적이고 상대적 비교를 강조하는 집단주의 문화를 가짐 으로써 소속과 사회적 인정에 대한 욕구가 강하게 나타나고 사회적 준거나 규범이 강조되어 개인주의 문화권에 비해 타인 과 자신을 비교하는 정도가 높기 때문이다(Jang, 2009). 일반 적으로 집단주의 문화에 속한 구성원은 사회적 목표, 관계, 역 할과 의무에 집중하는 반면, 개인주의 문화의 구성원은 개인 의 생각, 감정과 목표를 더 중요시하는 경향이 있다(White \& Lehman, 2005). 이러한 비교가 각자 처한 상황적 특수성을 반 영하지 않은 채 단순한 결과만을 토대로 이루어진다면 자신에 대한 부정적인 평가로 이어질 가능성이 더 높고 사회불안을 경험할 가능성도 증가하게 된다. 그러므로 타인과의 비교를 지양하고 각 개인의 개성과 자율성을 존중해 주는 사회적 분 위기가 형성되는 것이 필요하다.

둘째, 중학생이 부적응적인 인지적 정서조절전략 중에 파 국화 전략을 많이 사용할수록 사회불안을 더 경험할 수 있는 것으로 나타나 자신이 직면한 부정적 사건이 최악의 상황이 라고 생각할수록 사회불안을 더 많이 경험함을 보여주었다. 이러한 결과는 선행연구(D. Lee \& Park, 2017; Stopa \& Clark, 2000)와 일치하는 것으로써 파국화 전략을 많이 사용하는 사 람들은 부정적인 요소가 있는 사회적 상황에 대해 최악의 상 황을 가정하며 극단적으로 해석하기 때문에 그와 같은 상황을 
회피하고자 하였을 가능성을 시사하고 있다. 이와 같은 본 연 구의 결과에 기초해 보면, 파국화 전략의 사용으로 인해 사회 불안이 야기될 가능성을 감소시키기 위해 다음과 같은 방안 을 고안해 볼 수 있다. 파국화 전략은 일어난 사건에 대해 부정 적인 측면과 심각성을 과도하게 강조하고 인지적 오류를 가진 사고이기 때문에 중학생들이 자신이 직면한 사건에 대해 합리 적이고 객관적으로 해석할 수 있도록 도움을 주어야 한다. 예 를 들어 인지행동치료(cognitive behavioral therapy)는 역기능적 인 자동적 사고가 의식하지 못한 채로 발생할 수 있지만 주의 를 집중할 경우 인지할 수 있다는 주장에 기반하여 자동적 사 고를 찾고 이를 수정함으로써 합리적인 사고방식을 가지도 록 도움을 주므로 이 접근 방법을 적용해 볼 수 있다(Wright, Basco, \& Thase, 2009). 즉, 합리적인 사고를 할 수 있도록 사고 기록지에 사건, 자동적 사고와 감정을 기록한 다음 합리적 반 응과 인지의 변화가 가지고 오는 성과를 추가로 기록하여 역 기능적인 자동적 사고를 스스로 수정하고 이를 파악할 수 있 게 도울 수 있다.

한편, 부적응적인 인지적 정서조절전략 중에 자기비난, 타 인비난, 반추는 사회불안에 직접적인 영향을 미치지 않는 것으 로 나타나 선행연구(D. Lee \& Park, 2017; You et al., 2018)와 상 반된 결과를 보여주었다. 부적응적인 인지적 정서조절전략은 부정적인 사고와 정서를 심화시킴으로써 사회불안에 영향을 미치는 것으로 주장되어 왔으나 Garnefski 등(2001)이 설명한 바와 같이 부적응적인 인지적 정서조절전략이라 하더라도 상 황에 따라 적응적으로 작용할 수 있는 경우도 예외적으로 존재 할 수 있으며, 이 주장에 근거하여 본 연구결과를 해석해 볼 수 있다. 앞서 언급했듯이 파국화는 어떤 상황에서든지 극단적으 로 생각하여 가장 부정적인 결과를 가정하는 전략인데 반해 자 기비난, 타인비난 그리고 반추는 상황에 따라 부적응적인 기능 을 하지 않았을 가능성도 있다. 즉, 자기비난의 경우 자신을 비 난하는 과정에서 통제할 수 없는 상황보다는 자신에게 원인을 둠으로써 변화를 위해 노력할 수 있다는 가능성을 배제할 수 없다. 타인비난의 경우에는 타인에게 책임을 전가함으로써 자 신을 부정적으로 평가하지 않기 때문에 사회불안이 유발되지 않을 수 있다. 또한 반추 전략도 이와 마찬가지로 자신의 상황 을 되새김질하는데, 부정적인 생각과 감정에 빠져있는 것 대신 자신의 감정과 생각에 주의를 기울이고 관심을 가지는 역할로 작용했을 가능성이 있다(Treynor, Gonzalez, \& Nolen-Hoeksema, 2003). 뿐만 아니라 상관관계 분석의 결과에 나타난 바와 같이, 부적응적인 인지적 정서조절전략의 네 가지 전략 간의 상관계 수가 높았던 점을 고려해볼 수 있다. 즉, 각 하위 전략은 모두
종속 변인과 유의한 상관이 있었으나, 각 전략들 간의 높은 상 관으로 인해 파국화를 제외한 나머지 전략들의 영향이 유의하 지 않게 나왔을 가능성을 배제할 수 없다.

연구문제 2 와 관련하여 사회비교 경향성이 중학생의 사회 불안에 미치는 영향이 부적응적인 인지적 정서조절전략에 따 라 다른지 검증한 결과, 사회비교 경향성이 중학생의 사회불 안에 미치는 영향이 부적응적인 인지적 정서조절전략의 하위 요인 중 하나인 반추 전략의 사용 수준에 따라 다른 것으로 나 타났다. 중학생이 부정적인 사건으로 유발된 생각과 감정에 대해 빠져있고 지속적으로 곱씹는 경향이 클 경우, 타인과 자 신을 비교하는 사회비교 경향성이 사회불안을 야기할 가능성 이 더 컸음을 의미한다. 이러한 결과는 사회불안을 설명하는 여러 이론적 관점에서 반추가 사회불안을 유지시키는 데 중요 한 작용을 한다는 주장(Clark \& Wells, 1995)과 청소년이 반추 전략을 많이 사용할수록 타인의 기준에 도달해야 한다는 인지 적 성향으로 인한 학업 스트레스가 시험과 같은 평가 상황에 대한 두려움에 미치는 영향이 증가한다는 주장(Jeong, Kim, \& Shin, 2017)과 맥락을 같이 한다.

흥미롭게도 본 연구에서는 중학생의 사회불안에 대한 반추 전략의 직접효과는 유의미하지 않는 반면, 반추 전략이 사회 비교 경향성과 사회불안의 관계에서 유의미한 조절효과를 가 지는 것으로 나타났음에 주목할 필요가 있다. Y. A. Kim, Oh, Moon과 Kim (1999)은 심리적으로 적응적인 모습을 보이는 집 단에서는 반추 전략이 개인의 내적 측면에 대한 인식을 높임 으로써 긍정적으로 작용할 수도 있지만, 부적응적인 집단에서 는 부정적인 정서를 더 심하게 악화시키는 기능을 한다고 주 장한 바 있다. 이와 같은 주장에 기초해 보면, 사회비교 경향 성이 높은 사람은 자신과 자신의 상황에 대해 객관적인 인식 을 하는 데 어려움이 있고 타인의 시선과 평가에 민감한 경향 이 있기 때문에 사회불안이 유발될 수 있는데, 이러한 사람들 이 반추 전략을 사용하게 되면 사건이 끝난 이후 혹은 실제로 경험하지 않은 사건에 대해서도 편향적인 사고로 해석하고 타 인의 예상되는 시선과 평가에 대해 계속 부정적으로 예측함으 로써 사회불안이 더 심화될 수 있다고 해석할 수 있다. 이상과 같은 반추 전략의 조절효과는 비록 사회비교 경향성이 높다고 하더라도 반추 전략을 덜 사용하도록 함으로써 사회불안을 완 화시키거나 최소한 악화되지 않게 방지할 수 있다는 것을 보 여준다는 점에서 의의가 있다.

반추 전략의 조절효과에 기반한 개입 방안이 중요한 이유 는 우리나라의 문화적 특성과 중학생의 교육 환경과 관련이 있다. 앞서 언급한 바와 같이 사회비교 경향성을 감소시키는 
것이 하나의 방안임은 분명하나, 우리나라의 경우 문화적 특 성과 중학교의 교육 분위기로 인해 우리나라 중학생들의 사회 비교 경향성을 감소시키는 중재만으로는 사회불안을 효과적 으로 감소시키기 힘들기 때문에 반추 전략의 개입을 통한 사 회불안 감소가 현실적일 수 있다. 구체적으로 H. J. Kim과 Son (2007)은 긍정적인 기억 떠올리기, 자신을 허용적인 태도로 대 하기, 문제해결적인 관점 갖기 등이 반추 사고의 감소에 효과 적이라고 언급하였다. 이러한 대안적 사고는 자신이 경험한 사 건을 그대로 받아들이는 수용, 부정적인 사건에 대해 부정적인 측면에만 집중하지 않고 자신의 성장과 관련시켜 재해석하는 긍정적 재평가, 실제로 일어난 일 대신 즐거웠던 다른 일들을 생각하는 긍정적 초점변경과 상황을 개선하기 위한 대처방식 을 찾으려 하는 계획 다시 생각하기 등의 적응적인 인지적 정 서조절전략과 유사하다(Garnefski et al., 2001). 즉, 사회비교 경 향성이 높아 현실을 객관적으로 인식하지 못하면서 부정적인 편향적 인지를 하는 중학생들에게 적응적인 인지적 정서조절 전략을 대안적인 인지 방법으로 사용하게 한다면 사회불안 완 화에 도움이 될 것으로 생각된다. 또한 자신이 반추 전략을 사 용하고 있다는 것을 스스로 인지하고 부정적인 생각이나 걱정 에 압도되지 않으며 현재의 경험에 집중하는 것은 반추 전략을 감소시켜 사회비교 경향성이 높은 중학생들의 사회불안이 완 화되는 데 도움이 될 것으로 보인다(G. Lee \& Kim, 2016).

한편, 반추 전략을 제외한 나머지 부적응적인 인지적 정서 조절전략의 조절효과는 유의하지 않았다. 반추 전략은 사회적 상황이 이미 종료된 이후와 실제로 발생하지 않은 상상 속의 사건에 대해서 객관적이지 못한 사고로 해석을 했을 경우 부 정적인 인지와 정서를 지속시키고 심화시키는 데 반해 자기비 난, 타인비난 그리고 파국화 전략은 직접 사건을 직면했을 때 서로 다른 방식으로 부정적이고 편향적으로 해석하는 전략이 다(Garnefski et al., 2001). 이와 같은 차이에 기초해 볼 때, 사회 비교 경향성이 사회불안에 가지는 설명력이 강하다고 하더라 도 반추 전략은 사회비교 경향성이 사회불안에 영향을 미치는 과정에서의 부정적인 측면을 더 심화시킬 수 있기 때문에 조 절효과가 유의했다. 반면 자기비난, 타인비난 그리고 파국화 는 객관적인 인지를 하지 못하게 하는 요인이지만 그러한 인 지를 더 강하게 만드는 기제는 아니며 사회비교 경향성의 설 명력보다 상대적으로 약하기 때문에 조절효과가 유의하지 않 을 가능성을 배제할 수 없다.

마지막으로 본 연구에 대한 제한점을 밝히면서 후속연구 를 위한 제언을 하면 다음과 같다. 본 연구에서 사용한 측정 도 구는 자기보고식 척도였는데, 이는 본 연구의 측정변인인 사
회불안, 사회비교 경향성, 부적응적인 인지적 정서조절전략 은 응답자 자신이 가장 정확한 평가를 내릴 수 있는 변인이라 고 판단하였기 때문이다. 그러나 이 변인들은 모두 부적응적 인 변인으로서 부정적인 내용을 포함하고 있어서 응답에 사회 적 바람직성에 의한 편향(social desirability bias)과 답을 하기 어 렵거나 솔직하게 응답하고 싶지 않은 문항에 대하여 집중경향 오류(central tendency error)가 발생하였을 수 있다는 점에서 한 계가 있다. 따라서 후속 연구에서는 연구 대상이 또래들과 교 사와 함께 있는 학교 교실과 같은 환경보다 단독으로 별도의 공간에서 응답하도록 하거나 응답해야 하는 문항들에 대해 누 구나 경험할 수 있는 보편적인 것이라는 것을 사전에 고지해 주는 등 대상이 솔직하게 말하고자 하는 동기를 높여줌으로써 (Tourangeau \& Yan, 2007) 이상의 제한점을 보완하고 보다 신 뢰로운 측정치를 얻을 수 있을 것으로 사료된다.

위와 같은 제한점에도 불구하고, 본 연구가 지니는 시사점 은 다음과 같다. 첫째, 본 연구는 중학생을 대상으로 사회비교 경향성과 사회불안의 관계를 검증하였는데 지금까지 성인을 대상으로 했던 선행연구와 같이 상향비교든 하향비교든 상관 없이 타인과 자신을 자주 비교하는 것이 중학생의 경우에도 사회불안에 영향을 미친다는 것을 검증하여 성인과 마찬가지 로 사회비교 경향성의 감소가 사회불안을 감소시키는 데 효과 적인 방법임을 알 수 있었다. 본 연구의 결과는 수행평가와 각 종 시험 등의 일정이 많은 중학생들이 상향비교와 하향비교를 포함하여 어느 방향이든지 타인과 자신을 비교하는 것을 지양 하기 위해서 중학생 개인적 차원에서의 노력과 학교와 사회 적 차원에서 환경 변화가 함께 이루어져야 한다는 점을 시사 한다. 둘째, 지금까지 사회비교 경향성과 사회불안간의 관계 를 본 연구들은 이들의 직접적인 관계에만 초점을 두었지만, 본 연구는 사회비교 경향성과 사회불안의 관계에서 반추 전략 사용이 조절효과를 가짐을 보여주었다. 이러한 결과는 변화 나 개입이 쉽지 않은 사회비교 경향성이 높은 중학생들의 경 우 반추 전략 사용의 감소가 사회불안을 줄이기 위한 효과적 인 방안이라는 것을 시사한다. 이와 같이 본 연구의 결과는 중 학생의 사회불안을 예방하고 감소시키는 중재 방안을 계획하 는 데 도움이 될 수 있을 것으로 보인다.

\section{Notes}

This article is part of the first author's master's thesis submitted in 2019. 


\section{Conflict of Interest}

No potential conflict of interest relevant to this article was reported.

\section{References}

\section{In English}

Aiken, L. S., \& West, S. G. (1991). Multiple regression: Testing and interpreting interactions. Thousand Oaks, CA: SAGE Publications.

Aldao, A., Jazaieri, H., Goldin, P. R., \& Gross, J. J. (2014). Adaptive and maladaptive emotion regulation strategies: Interactive effects during CBT for social anxiety disorder. Journal of Anxiety Disorders, 28(4), 382-389. doi:10.1016/ j.janxdis.2014.03.005

Antony, M. M., Rowa, K., Liss, A., Swallow, S. R., \& Swinson, R. P. (2005). Social comparison processes in social phobia. Behavior Therapy, 36(1), 65-75. doi:10.1016/S00057894(05)80055-3

Baron, R. M., \& Kenny, D. A. (1986). The moderator-mediator variable distinction in social psychological research: Conceptual, strategic, and statistical considerations. Journal of Personality and Social Psychology, 51(6), 1173-1182. doi:10.1037/0022-3514.51.6.1173

Clark, D. M., \& Wells, A. (1995). A cognitive model of social phobia. In R. G. Heimberg, M. R. Liebowitz, D. A. Hope, \& F. R. Schneier (Eds.), Social phobia: Diagnosis, assessment, and treatment (pp.69-93). New York: Guilford Press.

Elkind, D. (1967). Egocentrism in Adolescence. Child Development, 38(4), 1025-1034. doi:10.2307/1127100

Franzoi, S. L. (1983). Self-concept differences as a function of private self-consciousness and social anxiety. Journal of Research in Personality, 17(3), 275-287. doi:10.1016/00926566(83)90019-3

Garnefski, N., Kraaij, V., \& Spinhoven, P. (2001). Negative life events, cognitive emotion regulation and emotional problems. Personality and Individual Difference, 30(8), 1311-1327. doi:10.1016/S0191-8869(00)00113-6

Gibbons, F. X., \& Buunk, B. P. (1999). Individual differences in social comparison: Development of a scale of social comparison orientation. Journal of Personality and Social Psychology, 76(1), 129-142. doi:10.1037/0022-3514.76.1.129

Gilbert, P., \& Miles, J. N. V. (2000). Sensitivity to social put-down: It's relationship to perception of social rank, shame, social anxiety, depression, anger and self-other blame. Personality and Individual Differences, 29(4), 757-774. doi:10.1016/
S0191-8869(99)00230-5

Hofmann, S. G. (2005). Perception of control over anxiety mediates the relation between catastrophic thinking and social anxiety in social phobia. Behaviour Research and Therapy, 43(7), 885895. doi:10.1016/j.brat.2004.07.002

Hofmann, S. G. (2007). Cognitive factors that maintain social anxiety disorder: A comprehensive model and its treatment implications. Cognitive Behaviour Therapy, 36(4), 193-209. doi:10.1080/16506070701421313

Inderbitzen-Nolan, H. M., \& Walters, K. S. (2000). Social anxiety scale for adolescents: Normative data and further evidence of construct validity. Journal of Clinical Child Psychology, 29(3), 360-371. doi:10.1207/S15374424JCCP2903_7

La Greca, A. M., \& Lopez, N. (1998). Social anxiety among adolescents: Linkages with peer relations and friendships. Journal of Abnormal Child Psychology, 26(2), 83-94. doi:10.1023/A:1022684520514

Mellings, T. M. B., \& Alden, L. E. (2000). Cognitive processes in social anxiety: The effects of self-focus, rumination and anticipatory processing. Behaviour Research and Therapy, 38(3), 243-257. doi:10.1016/S0005-7967(99)00040-6

Mesa, F., Nieves, M. M., \& Beidel, D. C. (2011). Clinical presentation of social anxiety disorder in adolescents and young adults. In C. A. Alfano \& D. C. Beidel (Eds.), Social anxiety in adolescents and young adults (pp.11-23). Washington, DC: American Psychological Association.

Mitchell, M. A., \& Schmidt, N. B. (2014). An experimental manipulation of social comparison in social anxiety. Cognitive Behaviour Therapy, 43(3), 221-229. doi:10.1080/16506073.20 14.914078

Paternoster, R., Brame, R., Mazerolle, P., \& Piquero, A. (1998). Using the correct statistical test for the equality of regression coefficients. Criminology, 36(4), 859-866. doi:10.1111/j.17459125.1998.tb01268.x

Rapee, R. M., \& Heimberg, R. G. (1997). A cognitive-behavioral model of anxiety in social phobia. Behaviour Research and Therapy, 35(8), 741-756. doi:10.1016/S0005-7967(97)00022-3

Schlenker, B. R., \& Leary, M. R. (1982). Social anxiety and selfpresentation: A conceptualization and model. Psychological Bulletin, 92(3), 641-669. doi:10.1037/0033-2909.92.3.641

Stopa, L., \& Clark, D. M. (2000). Social phobia and interpretation of social events. Behaviour Research and Therapy, 38(3), 273-283. doi:10.1016/S0005-7967(99)00043-1

Treynor, W., Gonzalez, R., \& Nolen-Hoeksema, S. (2003). Rumination reconsidered: A psychometric analysis. Cognitive Therapy and Research, 27(3), 247-259. doi:10.1023/A:1023910315561

Tourangeau, R., \& Yan, T. (2007). Sensitive questions in surveys. Psychological Bulletin, 133(5), 859-883. doi:10.1037/00332909.133.5.859

White, J. B., Langer, E. J., Yariv, L., \& Welch, J. C. (2006). Frequent 
social comparisons and destructive emotions and behaviors: The dark side of social comparisons. Journal of Adult Development, 13(1), 36-44. doi:10.1007/s10804-006-9005-0

White, K., \& Lehman, D. R. (2005). Culture and social comparison seeking: The role of self-motives. Personality and Social Psychological Bulletin, 31(2), 232-242. doi:10.1177/0146167204271326

Wright, J. H., Basco, M. R., \& Thase, M. E. (2009). Learning cognitive-behavior therapy (J. Kim, Trans.). Seoul: Hakjisa. (Original work published 2005)

\section{In Korean}

Baek, S. J. (2018). The effects of social comparison orientation and stress coping styles on job-seeking stress of university students preparing for employment (Master's thesis). Retrieved from http://www.riss.kr/link?id=T14858001

Choi, M.-K., \& Min, D.-G. (2015). The influence of parental behavior control and adolescents' anxiety on school related adjustment. Family and Environment Research, 53(4), 363373. doi:10.6115/fer.2015.029

Choi, Y.-H. (2003). The effects of stress, locus of control and social comparison orientation on level of depression (Master's thesis). Retrieved from http://www.riss.kr/link?id=T8945140

Ha, J.-H. (2006). The relationship between social comparison orientation, irrational beliefs and achievement goals on male and female adolescents. The Korean Journal of Educational Psychology, 20(4), 785-805.

Jang, E.-Y. (2009). Social comparison and adjustment in two cultures. Korean Journal of Social and Personality Psychology, 23(2), 157-169.

Jeong, A., Kim, E., \& Shin, H. (2017). The effects of sociallyprescribed perfectionism and academic stress on test anxiety: Moderated mediating effects of maladaptive cognitive emotional regulation strategies. The Korean Journal of School Psychology, 14(3), 281-304. doi:10.16983/kjsp.2017.14.3.281

Kim, H. J., \& Son, C. N. (2007). The effects of cognitive behavioral therapy on anxiety and depression of evaluative concerns perfectionistic undergraduate students. Korean Journal of Clinical Psychology, 26(4), 805-826.

Kim, J.-M. (2010). The role of self-esteem in the relationship between maladaptive perfectionism and depression in children and adolescents. Korean Journal of Youth Studies, 17(8), 79-104.

Kim, S.-H. (2004). A study on relationship among the stressful events, cognitive emotion regulation strategies and psychological well- being (Master's thesis). Retrieved from http://www.riss.kr/ link?id=T9560970

Kim, Y. A., Oh, K. J., Moon, H. S., \& Kim, J. K. (1999). Two psychological correlates of private self-consciousness. Korean Journal of Clinical Psychology, 18(1), 69-78.

Lee, D., \& Park, J. H. (2017). The effects of family differentiation on interpersonal anxiety in university students and the moderating role of maladaptive cognitive emotion regulation strategies. Korean Journal of Child Studies, 38(4), 65-78. doi:10.5723/kjcs.2017.38.4.65

Lee, G., \& Kim, E. (2016). The effects of mindfulness instruction on anxiety and post-event rumination in socially anxious undergraduate students. Korean Journal of Clinical Psychology, 35(1), 165-193.

Lee, S.-S., \& Jang, G.-E. (2007). The effects of cooperative group investigation method in social studies classes on the middle school students' academic attitude. Journal of The Korean Association of Regional Geographers, 13(5), 595-607.

Seo, E., \& Kim, J. (2018). Mediating effect of inferiority feeling between social comparison tendency and social anxiety university students. Institute for Humanities and Social Sciences, 19(2), 167-187.

Yang, J.-W., Yang, Y. R., \& Oh, K. J. (2008). Psychometric properties of the Social Anxiety Scale for Adolescents(KSAS-A) in Korea. Korean Journal of Clinical Psychology, 27(4), 861-878.

You, S. M., Kim, J. M., \& Kang, H. U. (2018). The effects of adolescents' irrational belief on social anxiety: Mediating effect of automatic thoughts, maladaptive self-focused attention, and rumination. Cognitive Behavior Therapy in Korea, 18(1), 85-104.

\section{ORCID}

Yujin Lee http://orcid.org/0000-0002-2013-0908

Ju Hee Park http://orcid.org/0000-0003-3031-0272

Received December 20, 2018

Revision received January 27, 2019

Accepted January 29, 2019 